\title{
A Framework for understanding \& classifying Urban Data Business Models
}

\author{
Shane McLoughlin \\ LERO, NUIM \\ shane.mcloughlin@mu.ie
}

\author{
Abhinay Puvvala \\ LERO, NUIM \\ abhinay.puvvala@mu.ie
}

\author{
Giovanni Maccani \\ School of Business, \\ NUIM \\ giovanni.maccani@mu.ie
}

\author{
Brian Donnellan \\ School of Business, \\ NUIM \\ brian.donnellan@mu.ie
}

\begin{abstract}
Governments' objective to transition to 'Smart Cities' heralds new possibilities for urban data business models to address pressing city challenges and digital transformation imperatives. Urban data business models are not well understood due to such factors as the maturity of the market and limited available research within this domain. Understanding the barriers and challenges in urban data business model development as well as the types of opportunities in the ecosystem is essential for incumbents and new entrants. Therefore, the aim of this paper is to develop a framework for understanding and classifying Urban Data Business Models (UDBM). This paper uses an embedded case study method to derive the framework by analyzing 40 publicly funded and supported business model experiments that address pressing city challenges under one initiative. This research contributes to the scholarly discourse on business model innovation in the context of smart cities.
\end{abstract}

\section{Introduction}

The paradigm of 'Smart Cities' as a response to increasing urban population, environmental pressures, budgetary restraints, legacy IT systems, ongoing city developments and renewal, as well as policy and rationales for bottom up city engagement and participation has opened up new possibilities for innovative business models propositioning urban data focused solutions as a response to pressing city challenges, and digital transformation imperatives [1]. Here, we define 'urban' as 'relating to a town or city' [2]. Reviewing existing definitions of 'Urban Data' [3] and 'Urban Big Data' [4], we define Urban Data as, data concerning one or more town or city spatial region(s) physical, social, cultural, political or economic environment. Thus, urban data is about a town or city region(s) citizens, its infrastructure, its businesses, government and natural environment etc. For example, 'Citymapper' offers wayfinding across several European cities leveraging such sources as open urban transport data, in order to offer its mobile app based solution. In recent years, business activity has focused on developing pilots, demonstrating prototypes with some offering commercial solutions to cities. However, the sustaining and scaling of an ecosystem of urban data business models has proved slow and in some cases fraught with difficultly. Compared to previous Data Driven Business Models (e.g. through open data from the public [5] or private [6] sector, or other data marketplaces), the context of urban data heralds specific technical, socio-political, ethical and economic challenges etc. Urban data may be existing data that can be purchased, reused for free, or even generated though development of sensing technology or crowdsourcing initiatives. These processes create value networks comprising of different actors [7] which significantly add complexity to business model creation [8]. Digitization and datadriven innovation or 'datification' [9] in an urban context therefore needs to overcome additional challenges.

As 'data' becomes seen as the 'new oil' and a critical source of new insight for cities, policy translating to research efforts in the EU has focused on developing a marketplace and supporting social innovation through the use of urban data through various capacity building exercises. Thus, the EU is playing a central role in promoting, fostering, and facilitating economic development and new business creation. Some of the most popular examples include federated Living Lab flavored initiatives like OrganiCity to support innovation [10] and SBIR (Small Business Innovation research) pre-commercial procurement mechanisms to promote innovation and collaboration among entities, sectors, businesses, and across cities themselves [11]. In this regard, Governmental funding and support to 'market make' new urban data ecosystems by funding research to address standards, interoperability and encourage experimentation for innovation; may lead to exponential growth of innovative value propositions. In this regard, vendors have struggled in developing sustainable business models due to continuing lags in standards, interoperability, data models, IoT and 
telecommunication network maturity, as well as budgetary constraints by cities etc.

It is hoped that a critical mass of differing urban data types and sources will unlock new opportunities for urban data focused business models by establishing network synergy in an urban data ecosystem. 'Scaling' is a crucial factor in realizing these opportunities as a minimum viable business case for a vendor could depend on multi-city/country take-up of an offering. In this regard, multi-city and multi-country experimentation by vendors is needed to develop solutions compatible across differing political-culturalenvironmental-social contexts.

Despite academic debate on how to conceptualize business models, there is agreement that Business Models articulates value creation [12]. Within the existing literature, there have been some efforts at formulating business model dimensions, classifications or taxonomies of; data-driven digital services [13], concept definitions across the data value chain [14], business models for open data [15] and data driven business models [16], [17], though no study has developed a framework that can apply a consistent language and lens to organisations focusing on urban data solutions. Such a framework can be fruitful for researchers as an analytical lens in (1) identifying and understanding challenges across the value network in developing urban data business models, (2) identifying opportunities for value propositions and related urban data business model combinations, and (3) substantiating commercially successful types of urban data business models out there. Thus, we pose the following research question:

RQ: What are the related value generating elements that inform differentiated value propositions and related urban data business models?

To address the research question, we case study the EU H2020 project OrganiCity [10] and the 40 experimental cases it has funded and supported to derive an Urban Data Business Model Framework. These cases are addressing city prescribed urban challenges, by developing innovative urban data business models through open innovation, co-creation and real-world (and in some cases multi-city) experimentation methods.

The remainder of this paper is organized as follows: Section 2 overviews the related literature on Business models, business model experimentation and existing frameworks and taxonomies of data driven business models. Section 3 describes the method including the case and sample. Section 4 describes the validated framework derived from the case-study. Finally
Section 5 concludes by comparing the framework to existing work and identifying future research work.

\section{Related Work}

Weill and Vitale [18] describe a business model as "the description of the roles and relationships among a firm's consumers, customers, allies, and suppliers that identifies the major flows of product, information, and money, and the major benefits to participants". Osterwalder et al. [19] defined a business model as a "conceptual tool that contains a set of elements and their relationships and allows expressing the business logic of a specific firm". Despite the presence of a myriad of business model definitions, there are few central tenets that are common across definitions, such as value creation logic for stakeholders; the consideration of crucial value creating activities performed by parties external to the company such as complementors, suppliers and customers; a comprehensive approach to explain the value creation logic of a company [20]. However, business model definitions are static and often fail to give a sense of firms in action.

Analysis of business models gives us a more dynamic sense of firms. The dynamic perspective is key to identify a firm's journey towards establishing a sustainable competitive advantage. However, the two widely accepted views - industry positioning view and dynamic capability view discuss the conditions for competitive advantage but do not elaborate on the journey towards it [21]. Industry positioning view proposes a truly differentiated position within an industry that can be defended to achieve competitive advantage [22]. Dynamic capability view argues that such an advantage can only be attained by developing competencies that are hard to replicate [23]. Moreover, McGrath [21] argues that business model innovation moves for competitive advantage can neither be strictly categorized as positional moves nor capability moves. Also, in the dynamic setting of technology based businesses, it is impossible to visualize the constraints that eventually prove to be competitively important at the time decisions pertaining to business model innovation need to be made. In such cases, experimentation is the preferred strategists' tool of choice than analysis. Further, business models' evolution is path dependent - early experiments often shape the future business model [21].

We also draw from the business ecosystems' literature for this study. The ever-growing interconnectedness associated with the networked economy prompted the research community to refocus on business ecosystems [24]. Moore [24] explains business ecosystems as an allegory of natural ecosystems in order to present the 
Table 1: Related Studies

\begin{tabular}{|llll|}
\hline Authors & Methodology & Research Question & Domain \\
\hline $\begin{array}{l}\text { Hartmann et } \\
\text { al. [16] }\end{array}$ & $\begin{array}{l}\text { Deductive study from } \\
\text { existing BM literature }\end{array}$ & $\begin{array}{l}\text { 1.Framework to analyse and compare DDBMs } \\
\text { 2.Taxonomy of Data Driven Business Models }\end{array}$ & $\begin{array}{l}\text { Data Driven } \\
\text { Business Models }\end{array}$ \\
\hline $\begin{array}{l}\text { Engelbrecht } \\
\text { et al. [17] }\end{array}$ & $\begin{array}{l}\text { Combination of } \\
\text { deductive and inductive } \\
\text { approaches }\end{array}$ & $\begin{array}{l}\text { To identify the dimensions of Data Driven } \\
\text { business model to develop a taxonomy }\end{array}$ & $\begin{array}{l}\text { Data Driven } \\
\text { Business Models }\end{array}$ \\
\hline $\begin{array}{l}\text { Schmidt et } \\
\text { al. [26] }\end{array}$ & Inductive study & $\begin{array}{l}\text { To develop a taxonomy of Fintech business } \\
\text { models }\end{array}$ & $\begin{array}{l}\text { Fintech Business } \\
\text { Models }\end{array}$ \\
\hline $\begin{array}{l}\text { Aya et al. } \\
{[13]}\end{array}$ & $\begin{array}{l}\text { Combination of } \\
\text { deductive and inductive }\end{array}$ & $\begin{array}{l}\text { 1.What characterizes data driven digital } \\
\text { services? }\end{array}$ & Data Services \\
& approaches & clustered? & To develop a framework that captures specifics \\
of IoT driven ecosystems & $\begin{array}{l}\text { IoT Business } \\
\text { Models }\end{array}$ \\
\hline Turber et al. & Design science research & Tigital services be & Moden \\
\hline
\end{tabular}

way companies should do business together. Ecosystems comprise of multiple actors working together that contributes to the ecosystem's core purpose despite having seemingly unrelated value propositions. Hence, the business ecosystem view includes a network of actors unlike that of a conventional value chain view which focuses on delivering a single value proposition to the end customer [25]. From an ecosystem point of view, we next review frameworks that map actors of business ecosystems that are closely connected to the urban data ecosystem. Table 1 has a snapshot of related studies in domains where data plays a vital role. Hartmann et al. [16] framework deals with data driven business models. Their study defines data driven business models as the businesses with data as a key resource. Though, Hartmann et al. [16] acknowledge that this criterion used for determining whether a business model is data driven or not is ambiguous, given the ubiquitous importance of data to all the business models. Moreover, despite the use of multiple case studies to cluster business models, the framework development lacks inductive case study based reasoning to develop the framework. Moreover, the framework's characterization of various second order elements leave scope for redundancies which in turn translate in to multi-collinearities between explanatory variables during cluster analysis. Schmidt et al. [16] have developed a similar taxonomy for Fintech business models. However, their study used Hartmann's [16] framework for representing 195 Fintech business models that were further clustered to derive 6 clusters, when put together represent the Fintech ecosystem.

Turber et al. [27] proposed a framework to map IoT business models on to a 3D space with dimensions representing the who, where and why of a business model. While the study represents an interesting way of mapping value creation across the ecosystem, it does not focus on capturing various intricacies associated with value creation, capture, configuration and delivery.

Engelbrecht et al. [17] too map data driven business models on to a 3-dimensional decision tree. The three dimensions (1) Data source (user/non-user), (2) Target audience (consumer/organization) and (3) Technological effort (high/low) derived from a study involving 'expert interviews'. The decision tree is used to map 33 data driven business models into 8 categories. Like Hartmann et al. [16], Engelbrecht et al. [17]'s work helps us to identify the higher order dimensions central to a data driven business model. However, unlike Hartmann et al. [16], Engelbrecht et al. [17] do not represent the granularity of sub dimensions composing data driven business models. Final, Aya et al. [13] study on data services focuses on service interactions between customers and service providers. The study focuses on the key activities necessary to understand data driven digital services, as 'Data Acquisition', 'Data Exploitation, 'Insights Utilization' and 'Service Interaction' [13].

Based on the review of related literature, we've identified the higher-order dimensions of an urban data business model with which to investigate cases to derive a framework. Although various Business model ontologies [19], Matrices [28] etc. identify various dimensions of a business model, we follow Hartmann et al. [16] approach (which has been utilized by IS researchers [26]) by focusing on the most commonly cited dimensions of a business model [16]. Hence, the higher level dimensions of the framework to explore consist of; 'Key Resources', 'Key Activities', 'Target Customer', 'Revenue Model', 'Value Proposition' \& 'Cost Structure'.

We have adopted a value proposition focused definition for the business models empirically 
examined for this study. For instance, a company that produces sensors to measure urban data may not qualify unless they include data management services in their offering portfolio. Thus, we define an Urban Data Business Model as a business model where urban data is central to the value proposition. This implicitly implies urban data is a key resource.

\section{Methodology}

\subsection{Research Design}

In the UDBM context, given its nature, we argue the conventional dichotomy between the social and the technical is problematic as technical and social choices are constantly negotiated and socially constructed [29]. Therefore, also given the exploratory nature of this study, an interpretivist approach has been chose to address the RQ [30].From an ontological perspective, this means that we investigate UDBM development as a complex phenomenon that is contingent on several social actors and activities. In order to capture this richness, inductive qualitative interpretive case study method was found to be suitable [31].

Although there are numerous definitions, Yin [32] defines the scope of a case study as follows: "a case study is an empirical inquiry that (1) investigates a contemporary phenomenon within its real-life context, especially when (2) the boundaries between phenomenon and context are not clearly evident" [32]. Hence, Case Study Research is a qualitative approach in which the investigator explores a bounded system (a case in a specific setting/context) over time, through detailed, in-depth data collection [33]. A 'holistic' case study is shaped by a qualitative approach focusing on a single unit of analysis, whereby an 'embedded' case study involves sub-units of analysis which focus on different salient aspects or levels of the case. These sub-units are specific and relevant aspects for answering the overall research questions [32]. Analysis of each sub-unit is completed 'within-level' before 'between-level' analysis occurs [32].

Inductive qualitative case study researchers usually combine multiple data collection methods [32] and keep the data collection and analysis processes flexible. Multiple sources of data were leveraged to "provide stronger substantiation of constructs" [34], i.e. the elements of the framework. In interpretive IS case studies, as an outside observer, Walsham [35] argues that interviews are the primary data source, "since it is through this method that the researcher can best access the interpretations that participants have regarding the actions and events which have or are taking place, and the views and aspirations of themselves and other participants" [35].

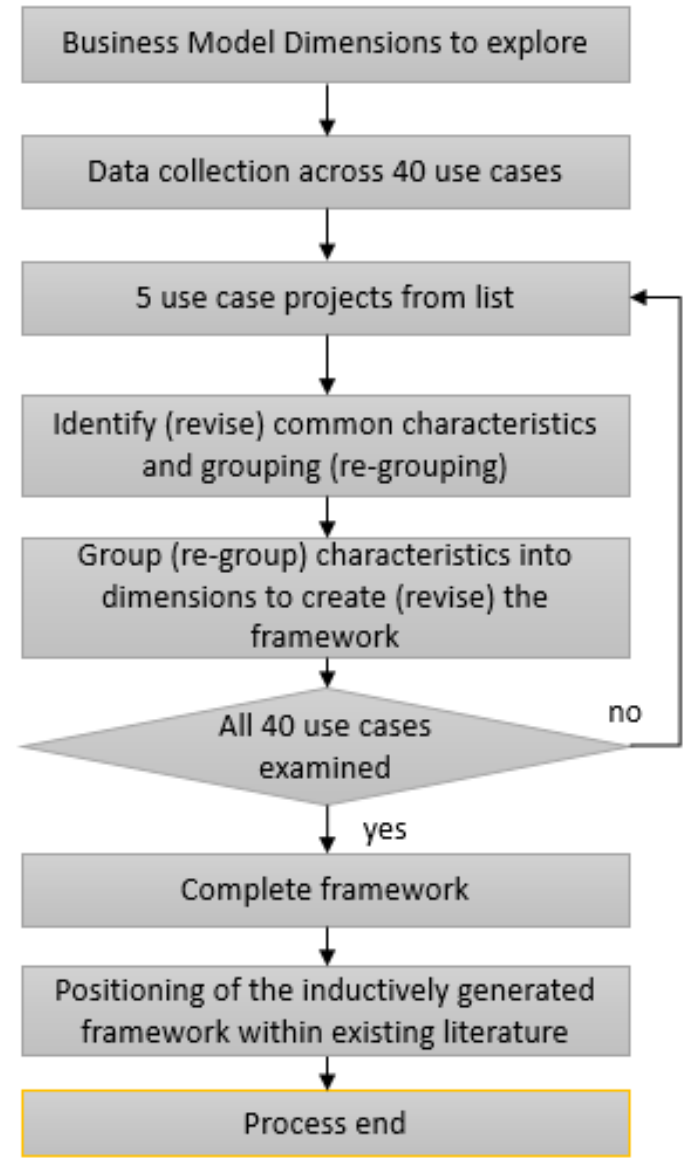

Figure 1.

\subsection{Case}

OrganiCity is a cross-European funding, support and IT capability mechanism for experimentation of new urban data driven solutions that address pressing city challenges. Its model is an 'Experimentation As A Service' facility. In essence it's a federated 'Living Lab' infrastructure across several European cities (e.g. London, Santander, Aarhus) with the goal of enabling and supporting innovative urban data solutions ranging from environmental pollution monitoring to new forms of citizen engagement. It works with cities in defining city challenges to fund, with a core principle of ' $\mathrm{Co}$ creation' and 'Real World Experimentation' in funding and supporting the defining of problems and reaching solutions. The rationale for its federated multi-city support and 'living lab' flavoured principles are to encourage the sustainability and scalability of the solutions emerging. Furthermore, it supports experimenters with a tool-kit of both IT capabilities that can aid experimentation as well as privacy, ethical and methodological guidance in carrying out 
experiments. In this regard, OrganiCity has gone through two open calls to fund and support over 40 European 'experimenters' ranging from Start-Ups, SME's to grassroots movements in ideating and developing prototypes that acquire and leverage urban data to deliver a urban data driven ecosystem, thus contributing to realising the 'Smart City'. Many of these experiments develop or leverage IoT, mobile and web apps, soft sensing interfaces and open data.

The first open call was open to individuals, associations, organisations or businesses legally registered, and awarded funding for each experiment of up to $60 \mathrm{k}$ euro as well as support and resources. Evaluation of proposals for 'experimentation' was by the 'OrganiCity Experiment Evaluation Committee (EEC)'. This committee consisted of two external experts, an OrganiCity Technical team member and one representative for each cluster city (Aarhus, London, Santander). Proposals were evaluated in terms of the novelty, impact and feasibility of the idea and the experimentation proposed, with co-creation expected as pillar of the experimentation. 'Experiments' or 'experimentation' was understood in terms of planning, staffing, co-creation activities, testing, prototyping and evaluation and reporting. Each Experiment Group had an appointed Experiment Lead, who coordinated the group and was responsible for providing feedback to OrganiCity [10].

\subsection{Data Collection}

In case-studying OrganiCity, we've interviewed over 30 of the 40 experimenters, interviewed city stakeholders across London $(\mathrm{N}=8)$, as well as collected and analyzed experimenter documents, reports, blogs, and publicly available information, as well as city policy strategies and OrganiCity reports. This helped us to understand both (1) OrganiCity and (2) the ecosystem of organisations and their journey of experimentation in developing the solutions. The data collected and thematically analysed contributes to our understanding of a European urban data driven ecosystem, and the development of urban data business models.

Upon initial analysis of the experimental cases, we identified 27 of the 40 experimenters were SME/Startup's and the rest related to NGO's, grass-roots initiatives, academic projects or multi-stakeholder partnerships. We included all cases as they could offer us insights into the data resources being leveraged, the technologies being developed, and the key activities undertaken to deliver solutions. Furthermore, although some of the experiments were not-for-profit social innovation focused organisations, they still wished to sustain the solution.
Over half of the cases $(52 \%)$ related to environmental solutions (i.e. Education, Air Quality, Vegetation, Sound, Water, Waste, Health), 12\% Social welfare (Housing, Security, Disabled, Health), 12\% multidomain, $10 \%$ mobility (Parking, wayfinding, carpooling), 5\% tourism, 3\% urban planning, 3\% Government procurement and 3\% sport.

Forty three percent had an IoT based experimental element (most of these sensor based), whilst the remainder concerned mobile apps, web platforms, data, or innovation in hardware based data interaction. Many relied on API's, whilst some drew on social media platforms.

\section{Validated Framework}

In this section, we describe the validated framework derived from an analysis of the cases. We use examples from the variety of cases where necessary to illustrate inclusion of the sub-dimensions, though this has been restrained due to the need for brevity. Details of all the cases can be accessed through the OrganiCity website at www.organicity.eu [10]. The framework (Figure 2.) is presented as an appendix at the bottom of this paper.

\subsection{Key Resources}

\subsubsection{Data}

In terms of 'Key Resources', both Engelbrecht et al. [17] and Hartmann et al. (2016) distinguish 'Data Sources' as the 'Key Resource'. For Hartmann et al. (2016), this is classified as 'internal' and 'external' data, whereby 'internal data' concerns data generated through crowdsourcing, sensing or tracking, or existing sources of internal data repurposed to deliver the value proposition. 'External' data is data acquired externally and further differentiated by such factors as 'freely available' data, 'customer provided' data, 'web tracked' data, 'open data' or 'social media' data etc. On the other hand, Engelbrecht et al. (2016) differentiated data source as 'User data' and 'Non User Data'. However, we argue that sourcing the data is a key activity, and not a key resource, whereby Hartmann et al. (2016) already captures 'data generation' and 'data acquisition' as an activity. Instead, we argue 'data' as the key 'resource' should focus on the nature of the data the company generates, repurposes or procures through the activity. The nature of the data as a 'key resource', can then be looked at in terms of its characteristics for delivering the value proposition. For example, 'open' data comprising of real-time geospatial pollution data may be procured from the city and over-layed with geo-spatial mobility 
data generated by IoT sensors, in order to deliver descriptive insights about the relationship between traffic and pollution. Importantly, the characteristics of the data has a bearing on such aspects as the resources and capabilities needed to leverage the data, as well as wider socio-political factors on its collection and use. For example, generating real time data may require greater storage, could have higher telecommunication costs, additional processing and analyzing capability, and may not be suitable to generate through low powered sensor devices. Auditory or visual data may involve additional privacy and security considerations, whilst open data may have sustainability concerns if a business is reliant on data's updating and longevity [36] etc. In all we found data could be characterized according to, 'Verocity', whether 'Real Time' streaming data or near 'Real Time' data (data sensed and uploaded very frequently), and 'Historical' data, all other data. For example, several experiments provided near 'Real Time' data by using low powered sensors, rather than 'Real Time' streaming. The 'Variability' of data was also a consideration, whereby 'Static' data refers to data unlikely to change over time. For example, data on the location of assets in the city, or 'Dynamic' data, which is data that is likely to change and thus requires frequent measurement. For example, Spend-network drew on both 'Static' and 'Dynamic' open data to offer insights to city councils. Data may also have variety in term of being 'Subjective' or 'Objective'. 'Subjective' data refers to 'user input' based data such as with the case of 'Tranquil City' where citizens identified tranquil spaces in the city, or 'Objective' data such as 'iCycle' (IoTee lab) which use IoT to measure the fill levels of bottle banks. The type of data, 'Auditory', 'Textual', 'Visual' or 'Numerical' was also an important distinction in the proposed solution offered, and the resources and activities needed to capture and the data and deliver the solution. For example, citizens 'Textual' annotation of IoT sensed 'Numerical' data is used by 'Camon' to combine 'Objective' and 'Subjective' air quality levels. Finally, we distinguish the 'Domain' of urban data in terms of 'Environment', 'Citizens', 'Cultural', 'Business', 'Mobility', 'Infrastructure', 'Government'. For example, 'Infrastructure' data relates to urban spaces and places and facilities in the city including buildings, parks, power supplies etc. This may relate to unused or vacant spaces in the city, such as is the solution from the social enterprise, 'Space Engagers'. 'Environmental' data refers to data about the natural environment of the city such as air and water, wildlife, or even soil and grass such as the case of experimenters 'Green Roof Monitoring'. 'Citizens' data refers to any data about citizens or communicated by citizens. For example,
'Data on Site' proposes new ways for citizens to interact and submit data about the city. 'Government' data relates to data about city governance and council activities and processes, as was the case for 'Spend Network' who drew on open data to offer insight into public sector sending. 'Cultural' data refers to data about history, events, social activities etc. in the city, such as for 'Walks in the City' developed a map to recommend places and spaces' for senior walkers. Finally, 'Mobility' relates to traffic, travel and wayfinding related data in the urban context. For example, 'Traffic controlled by air quality', which aimed to improve movement of traffic to improve air quality levels.

\subsubsection{Hardware and Software}

Not only will the nature of data needed to deliver the value proposition have implications for resources and activities of an organization, but the hardware and software resources suggest the type of value proposition an organization offers, whether in capturing data and delivering data or insights. For example, to offer a city and its citizens 'analytics as a service' of real-time air-pollution levels, an organization may require; (1) installing IoT (Internet of Things) 'hardware' 'sensors' on assets across the city in order to 'capture' data, (2) a 'hardware' 'user interface' combined with 'app based' 'software' installed in public places in order to 'deliver' 'descriptive' insights to citizens, as well as (3) 'browser based' 'software' in order to 'deliver' 'predictive' insights to city officials.

Thus, we further differentiate 'Key Resources' in terms of 'Hardware' and 'Software' needed to 'Capture' data, and 'Deliver' data and/or insights through the value proposition. Whilst Engelbrecht et al. (2016) identify 'technological effort required' in distinguishing data driven business models, this study proposes both 'Key Resources' (in terms of Hardware \& Software), and Key Activities elucidates how urban data business models are identified. Therefore, in terms of hardware, a 'Sensor Device' such as an IoT device may be used to capture 'objective' noise levels across the city, such as with the Belgium organisation, 'Sensifai'. A 'User Interface' may be installed for the public to capture 'subjective' views of sound levels by citizens, and then aggregated, analyzed and visualized in delivering prescriptive recommendations to city officials through a hardware 'User Interface', and delivered to citizens through an 'App Based' mobile software program. For example, 'Research X Design' (Data on Site) developed a toolkit solution for public participation, whereby voting hardware and software devices are installed on city assets. 'Empati' designed 
mobile flower pot style interfaces to place in city parks to gather subjective feelings of citizens.

\subsection{Key Activities}

Following Rizk et al. (2018), we propose that 'Data Acquisition' is a key activity whereby an organization draws on; (1) hardware or software resources such as 'sensors', 'trackers' or 'User based input' interfaces to 'generate' data, (2) software resources to 'procure' either 'Open' or 'Proprietary' data, or (3) existing data resources internal to the organization, i.e. 'Repurpose'. We further distinguish, 'Data Exploitation' [13] and 'Data Visualization' as sub-dimensions of 'Key Activities'. 'Data Exploitation' aims to create additional value from the data through, 'processing', 'analyzing' and 'simulating' data. By 'processing' we mean 'preparing', (cleaning, structuring etc.), 'aggregating' (combining datasets or different types of datasets) and/or 'transforming'(converting, or modifying) data [37], which is a lower degree of data exploitation and abstraction. 'Analysis' and 'Simulation' are a higher level of 'Data Exploitation' aiming at extracting knowledge i.e. insights (Rizk et al. 2018). These can be classified as 'descriptive' (summarize or report patterns \& relationships), 'predictive' (analyses data to make predictions), 'or 'prescriptive' (identifies options or recommends) insights [16]. 'Simulation' refers to the recreation of a complex system to run various 'what if' scenarios, and assess the behavior of the actual system.

Finally, 'Data Visualisation' [38] concerns the activity with which the exploited data may be presented to the end use. Converting complex information into visually engaging charts and images is a very niche value proposition few firms specialize in. Usually, firms couple the visualization capability with other key activities such as analytics rather than offering it standalone. 'Edinburgh CitySounds' is one such experiment selected for the second phase of OrganiCity. The experiment captures sounds by installing 'Auditory' data 'Sensor' Devices (AASs) across the city. These AASs will capture short clips of ultrasonic and audible noises of bats, birds and other wildlife, traffic, and human activity in real time. These sounds in-turn are combined with other data sets such as light, temperature, humidity, pollution to answer questions pertaining to the impact of human activity on animal behavior, changes in human/animal behavior with exogenous variables etc. It is imperative for Edinburgh CitySounds to develop visual standards to represent these seemingly unstructured, inconsistent, incoherent data sets, in doing so greatly enhance the utility of the final offering.

\subsection{Target Customers}

The basic premise of an OrganiCity experiment is to tackle an urban challenge. Consequently, the experimenters would look to deliver to any one or more stakeholders in an urban setting. Stakeholders such as citizens, other businesses, city councils/governmental organizations could all be the key customers for experimenters. Moreover, unlike traditional businesses that mostly focus on one customer segment at a time, business models in an urban setting have a more complex interwoven nature with various stakeholders. Often seen are experimenters that deal with multiple customer segments at the same time. This is also seen as a way of achieving larger market needed for eventual viability of the business model.

Green roof monitoring, an Oslo based experiment, is an example for operating in multiple target customer segments. It offers multi-sensorial monitoring of vegetation for citizens, businesses and the municipality. Another experimenter, 'Leapcraft', a sensing platform to measure air quality has the city council as a target customer.

\subsection{Revenue Models}

As discussed earlier, most of these experimenters are still in the process of discovering stable revenue streams. Some of these experiments, in their current state, only lend support to the experimenting firm's other businesses without generating any revenues themselves. Moreover, revenue models, like other business model components, are prone to frequent changes. We have observed 6 different revenue models adopted or planned by experimenters to extract value from their offerings: Asset sale, Usage fee, Leasing, Licensing, Subscription fee, Brokerage fee and Advertising fee. For instance, 'Wayfindr' provides its customers consultation for setting up audio navigation services and charges a (usage) fee. While, 'Airpublic' provides insights on the air quality to the city councils that subscribe to its services. FSTR licenses the use of its carpooling application to businesses which in turn make it available for their employees.

Further into each of these revenue models is the actual pricing mechanism for services and/or products. Osterwalder's (2004) three broad characterizations of pricing mechanisms - fixed, differential and market based have been used by experimenters. Predictably, most of the experimenters that deal in the B2B and B2G segments, owing to their relative lack of bargaining power while dealing with larger businesses, have been playing the role of price taker rather than price maker. It has also been observed that the only a handful of experimenters with IP protected assets were able to take the lead and set prices. 


\subsection{Cost Structure}

On the continuum of value driven to cost driven, we have observed that most of the OrganiCity experimenters are aligned closer to value driven extreme. It could be due to an emphasis on innovative and novel solutions rather than cost effective solutions by the reviewers. Having said that, there are a few experimenters who are focused on delivering solutions in a cost-effective way.

Empati and Leapcraft are examples of cost driven experimenters. Each one of them deliver solutions seeking to capture a market by offering a lower cost solution. For example, Leapcraft seeks to lower the cost of measuring air pollution and increase spread by developing mobile based air quality sensors that traverse the city on vehicles. Besides, OrganiCity is created as a platform to facilitate experimentation. Facilitating experimentation includes minimizing overheads needed to run these experiments. By providing technical expertise, a legal framework and access to data sets, the platform has provided a frictionless environment for innovation. However, since all the experimenters have common access to these facilities, we have not delved deep in to these provisions/factors as they do not distinguish between experiments.

\section{Conclusion \& Future Work}

This study has presented a framework of Urban Data Business models, defined as a business model where urban data is the central to the value proposition. We analyzed 40 urban data focused experimental cases under the umbrella of the EU H2020 OrganiCity to inductively derive the framework. The framework composes 5 higher level dimensions based on the 6 dimensions we identified from the literature review. Through the exercise of developing the framework, we determined that 'Value Proposition' will logically flow from other higher level dimensions of the framework, and thus was not included in the final framework. In otherwards, 'data' or resulting 'knowledge' or 'insight' is reflected through the activities a business undertakes to exploit and visualize the data, and thus captured through the framework. This also avoids the problem of multi-collinearity which would affect subsequent clustering of business model types when applying the framework.

Through the analysis of cases, we determined that 'Key Resources' should compose of both urban data capturing and delivering hardware and software, as these were a core offering of many of the cases we explored. Comparing the existing literature this is implicitly to referred by [13] as product or application based 'Service Interaction', by [17] as 'Technological effort', and by Hartmann et al. [16] through subdimensions of 'data sources' and 'data generation'.

As a result of the literature review, the variables in our framework have carefully been identified to avoid inter variable redundancies, thereby making the framework amenable for developing a taxonomy of urban data business models. For example, we argue that sourcing the data is a key activity, and not a key resource, whereby Hartmann et al. (2016) already captures 'Data Generation' and 'Data Acquisition' as an activity in addition to capturing these through the 'key sources' that he distinguishes.

As touched on in the introduction, we believe the framework can be useful for researchers allowing the applying of an analytical lens in (1) understanding challenges across the value network in developing urban data business models, (2) identifying opportunities for value propositions and related urban data business model combinations, and (3) substantiating the types of urban data business models. Furthermore, the Framework may be drawn on by practitioners in assessing proposals for funding and support, including viability in the context of the funding and the challenges with which to develop a solution.

The next stage of the study will be to apply the framework to OrganiCity supported cases to cluster and classify business models types. We furthermore plan to apply the framework to existing businesses which have already established a sustainable business model to identify trends in the industry.

This work was supported with funding from Science Foundation Ireland grant 13/RC/2094 and Intel Labs Europe.

\section{References}

[1] C. Loebbecke and A. Picot, "Reflections on societal and business model transformation arising from digitization and big data analytics: A research agenda," J. Strateg. Inf. Syst., vol. 24, no. 3, pp. 149-157, 2015.

[2] Oxford English Dictionary, "Oxford English Dictionary Online," Oxford English Dictionary, 2017. [Online]. Available: http://dictionary.oed.com.

[3] A. Wolff, G. Kortuem, and J. Cavero, "Urban Data in the primary classroom: bringing data literacy to the UK curriculum," Data Lit. Work., vol. 12, pp. 57-82, 2015.

[4] Y. Pan, Y. Tian, X. Liu, D. Gu, and G. Hua, "Urban Big Data and the Development of City Intelligence," Engineering, vol. 2, no. 2, pp. 171-178, 2016.

[5] A. Zuiderwijk, M. Janssen, and Y. K. Dwivedi, 
"Acceptance and use predictors of open data technologies: Drawing upon the unified theory of acceptance and use of technology," Gov. Inf. Q., vol. 32, no. 4, pp. 429-440, 2015.

[6] E. Lakomaa and J. Kallberg, "Open data as a foundation for innovation: The enabling effect of free public sector information for entrepreneurs," IEEE Access, vol. 1, pp. 558-563, 2013.

[7] Y. Tammisto and J. Lindman, "Definition of open data services in software business," in Lecture Notes in Business Information Processing, 2012, vol. 114 LNBIP, pp. 297-303.

[8] M. Janssen, Y. Charalabidis, and A. Zuiderwijk "Benefits, Adoption Barriers and Myths of Open Data and Open Government," Inf. Syst. Manag., vol. 29, no. 4, pp. 258-268, 2012.

[9] R. Maull, P. Godsiff, and C. E. A. Mulligan, "The impact of datafication on service systems," in Proceedings of the Annual Hawaii International Conference on System Sciences, 2014, pp. 11931201.

[10] EU, “Organicity,” 2017. [Online]. Available: http://organicity.eu/.

[11] EU, "Horizon 2020," 2018. [Online]. Available: https://ec.europa.eu/programmes/horizon2020/.

[12] M. Hossain, "Business model innovation: past research, current debates, and future directions," $J$. Strateg. Manag., vol. 10, no. 3, pp. 342-359, 2017.

[13] A. Rizk, B. Bergvall-kåreborn, and A. Elragal, "Towards a Taxonomy of Data-driven Digital Services," vol. 9, 2018.

[14] E. Curry, "The big data value chain: Definitions, concepts, and theoretical approaches," in New Horizons for a Data-Driven Economy: A Roadmap for Usage and Exploitation of Big Data in Europe, 2016, pp. 29-37.

[15] F. Ahmadi Zeleti, A. Ojo, and E. Curry, "Business Models for the Open Data Industry: Characterization and Analysis of Emerging Models," 15th Annu. Int. Conf. Digit. Gov. Res. (dg.o 2014), pp. 215-226, 2014.

[16] P. M. Hartmann, M. Zaki, N. Feldmann, and A. Neely, "Capturing value from big data - a taxonomy of data-driven business models used by start-up firms," Int. J. Oper. Prod. Manag., vol. 36, no. 10, pp. 1382-1406, 2016.

[17] A. Engelbrecht, J. Gerlach, and T. Widjaja,

"Understanding the Anatomy of Data-driven

Business Models - Towards an Empirical

Taxonomy," ECIS 2016 Proc., p. 16, 2016.

[18] P. Weill and M. R. Vitale, "Place to Space: Migrating to eBusiness Models.," Harvard Bus. Sch. Press Books, p. 1, 2001.

[19] A. Osterwalder and Y. Pigneur, "Clarifying Business Models : Origins, Present, And Future Of The Concept" vol. 15, no. May, 2005.

[20] D. Kiel, C. Arnold, and K. I. Voigt, "The influence of the Industrial Internet of Things on business models of established manufacturing companies - A business level perspective," Technovation, vol. 68, no. October, pp. 4-19, 2017.
[21] R. G. McGrath, "Business models: A discovery driven approach," Long Range Plann., vol. 43, no. 2-3, pp. 247-261, 2010.

[22] M. E. Porter, "Towards a dynamic theory of strategy," Strateg. Manag. J., vol. 12, no. 2 S, pp. 95-117, 1991

[23] D. J. Teece, "Explicating dynamic capabilities: The nature and microfoundations of (sustainable) enterprise performance," Strateg. Manag. J., vol. 28, no. 13, pp. 1319-1350, 2007.

[24] J. F. Moore, "Predators and prey: a new ecology of competition.," Harv. Bus. Rev., vol. 71, no. 3, pp. 75-86, 1993.

[25] M. F. Baghbadorani and A. Harandi, "A Conceptual Model for Business Ecosystem and Implications for Future Research," in International Proceedings of Economics Development and Research, 2012, vol. 52, pp. 82-86.

[26] J. Schmidt, P. Drews, and I. Schirmer, "Charting the Emerging Financial Services Ecosystem of Fintechs and Banks : Six Types of Data-Driven Business Models in the Fintech Sector," 2018.

[27] S. Turber, J. Vom Brocke, O. Gassmann, and E. Fleisch, "Designing business models in the era of Internet of Things: Towards a reference framework," 9th International Conference on Design Science Research in Information Systems and Technology, DESRIST 2014, vol. 8463 LNCS. Springer Verlag, Department of Innovation Management, University of St. Gallen, Switzerland, pp. 17-31, 2014.

[28] N. Walravens and P. Ballon, "Platform business models for smart cities: From control and value to governance and public value," IEEE Commun. Mag., vol. 51, no. 6, pp. 72-79, 2013.

[29] B. P. Bloomfield and T. Vurdubakis, "Boundary Disputes Negotiating the Boundary between the Technical and the Social in the Development of IT Systems," Inf. Technol. People, vol. 7, no. 1, pp. 9 24, 1994.

[30] G. Walsham, "Interpreting Information Systems in Organizations," Organ. Stud., vol. 15, p. 269, 1993.

[31] K. M. Eisenhardt, M. E. Graebner, A. M. Huberman, and M. B. Miles, "THEORY BUILDING FROM CASES," Acad. Manag. J., vol. 50, pp. 25-32, 2007.

[32] R. K. Yin, "Case Study Research . Design and Methods," SAGE Publications, vol. 26, no. 1.pp. 93-96, 2003.

[33] W. J. Orlikowski and J. J. Baroudi, "Studying information technology in organizations: Research approaches and assumptions," Inf. Syst. Res., vol. 2, no. 1, pp. 1-28, 1991.

[34] K. M. (1989). B. T. from C. S. R. A. of M. R. Eisenhardt, K. M.Eisenhardt, "Building Theories from Case Study Research.," Academy of Management Review, vol. 14, no. 4. pp. 532-550, 1989.

[35] G. Walsham, "Interpretative case studies in IS research: nature and method," Eur. J. Inf. Syst., vol. 4, pp. 74-81, 1995. 
[36] G. Maccani, B. Donnellan, and M. Helfert, "Open Data Diffusion for Service Innovation: An Inductive Case Study on Cultural Open Data Services," Proc. 19th Pacific-Asian Conf. Inf. Syst. (PACIS 2015), no. Walsham 1995, pp. 1-17, 2015.

[37] U. M. Fayyad, G. Piatetsky-Shapiro, and P. Smyth,
Advances in knowledge discovery and data mining. 1996.

[38] N. Elgendy and A. Elragal, "Big Data Analytics: A Literature Review Paper," Adv. Data Mining. Appl. Theor. Asp., vol. 8557, pp. 214-227, 2014.

\section{Appendix}

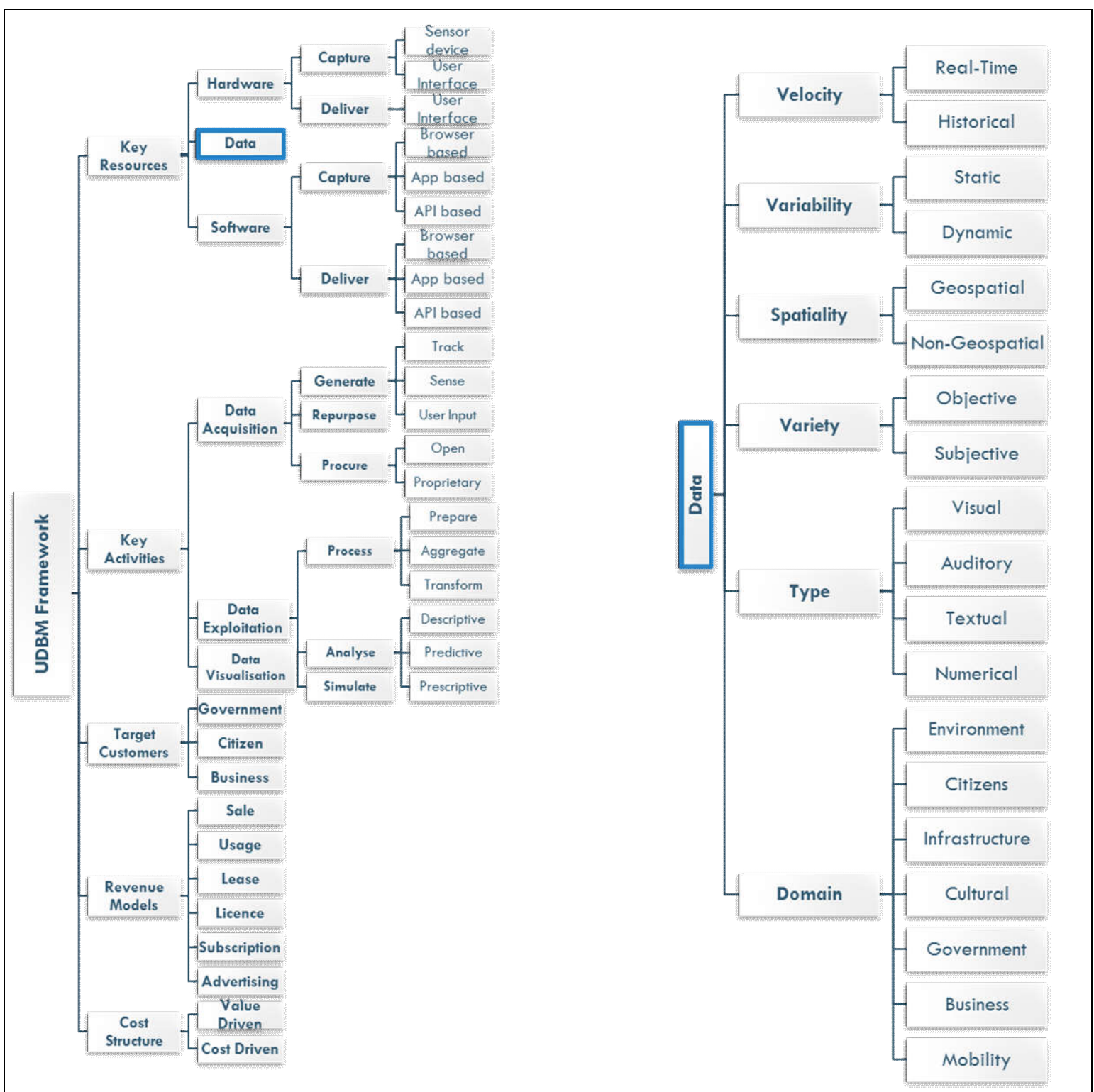

Figure 2. Urban Data Business Model Framework 